\title{
Expressando Emoções e Sentimentos no Facebook
}

\author{
Francielli Freitas Moro \\ Programa de Pós-Graduação em Informática na Educação \\ Universidade Federal do Rio Grande do Sul \\ Porto Alegre, RS, Brasil \\ franfm.moro@gmail.com
}

\author{
Luciana Bolan Frigo \\ Departamento de Computação \\ Universidade Federal de Santa Catarina \\ Araranguá, SC, Brasil \\ Luciana.frigo@ufsc.br
}

\begin{abstract}
Computer systems are increasingly adapting to user needs. Humanmachine interaction or human-computer interaction (HCI), as it is known, has discussed sociological approaches in order to design interfaces taking into account user's differences. This article presents an analysis of the Facebook social network based on the evolution of traditional HCI and some of its concepts for feminist HCI, thus exploring its functionality and evaluating it in this context. Surveys based on the concepts of feminist HCI were applied to evaluate this methodology and the impacts on gender diversity in these systems. The results indicate that most users seek more freedom to express themselves at the system and its content.
\end{abstract}

\section{KEYWORDS}

HCI Feminist, Gender, Women in Technology, Interaction Methodologies, Social Networks

\section{Introdução}

A Interação humano computador (IHC) é atribuída como um fator essencial no desenvolvimento de uma aplicação ou software desde o início dos anos 80. A partir desse conceito, surgiu a necessidade de padronizar os objetos de interação para unificar o modo como o usuário visualiza o sistema. Essa padronização foi importante para a construção das abordagens em torno da área, a fim de determinar objetivos, formas e definições. As metodologias tradicionais de IHC trazem uma visão prática do usuário para o sistema, mas são limitadas quanto a visão real que explora sensações, usabilidade e inclusão. Algumas metodologias vêm sendo discutidas e reformuladas atribuindo conceitos do estudo da psicologia, e alguns estudos sociológicos [1]. Neste sentido, pensando em incluir diversidades nas interfaces dos sistemas é necessário readequar as metodologias clássicas previamente abordadas em novas que atendam as particularidades dos usuários que os utilizam.

Em 2011, ocorreu na cidade de Vancouver, no Canadá, o ACM Conference on Human Factors in Computing Systems, onde foram apresentados diversos artigos e workshops de temas ligados à área de interface e interação e, entre os temas que mais chamaram atenção estava a IHC feminista. Em 2013, foi realizado um painel da ACM em Paris, considerando a baixa quantidade de pesquisas sobre gênero e IHC na literatura, a falta de abordagens para análise de fatores diagnósticos de ferramentas de software adequados à resolver problemas femininos, e o baixo apoio financeiro em pesquisas que visam explorar a representação da perspectiva feminista em um discurso atual [2]. Este tema e a integração de teorias feministas em metodologias tradicionais de IHC traz à tona diversas percepções e desafios de inclusão se tratando de tecnologia e design.

Existem diversas abordagens feministas, mas o feminismo igualitário costuma surgir com grande impacto nas discussões sobre feminismo. Ela é caracterizada por uma visão em que mulheres e homens são, para todos os fins legítimos, iguais; a igualdade é seu objetivo legal central e social [3].

Segundo [4] ideias estereotipadas de gênero são comumente usadas na construção de produtos/sistemas ditos femininos, como por exemplo o uso de uma cor específica para definir uma interface feminina, ou assumir o cuidado como prioridade feminina na construção de jogos digitais. Esse tipo de pensamento não ajuda a melhorar a inclusão de gênero em tecnologias e também exclui os homens como usuários desses produtos; ignora a diversidade significativa entre as mulheres em relação à cultura, raça, sexualidade, etc.; e também ignora os múltiplos gêneros que fazem parte de muitas culturas.

Existe uma grande diversidade de usuários nas redes sociais, e a padronização ao mesmo tempo em que facilita o trabalho dos desenvolvedores de sistema, limita e prejudica o acesso a tais sistemas de maneira a reduzir a inclusão digital.

Este artigo apresenta uma análise da rede social Facebook com relação à forma de interação e comunicação desta com seus usuários, no que tange a representação e expressão da vida real na vida virtual. Foi aplicado um questionário online em que 206 usuários da rede responderam a respeito das suas percepções no que tange a interação social na rede social. $\mathrm{O}$ objetivo principal dessa pesquisa é observar e prever a existência de aspectos referentes a IHC feministas nos objetos de interação do Facebook em comparação com as heurísticas tradicionais, de acordo com a percepção dos usuários respondentes.

\section{Interação Humano Computador}

A metodologia tradicional de IHC traz como objeto de estudo métodos de avaliação que focam mais no produto em questão do que no usuário e suas necessidades, buscando formas de interações padronizadas e não necessariamente funcionais. 
Segundo [5] a universalidade é um valor tradicionalmente associado à masculinidade e o protótipo do usuário é desenvolvido sob uma visão masculina, branca e heterossexual. Essa abordagem é estreita para perceber, definir e servir a população, mas continua a dominar a usabilidade e a avaliação do projeto. A partir dessa visão, os autores afirmam que no planejamento de um sistema deve-se considerar: (a) a interface, incluindo seu material perceptivo, assim como sua localização mais ampla nas línguas e culturas visuais e (b) a experiência do usuário, incluindo os significados, comportamentos, percepções, afeto, ideias e sensibilidades sociais que surgem no contexto da interação e seus resultados.

A metodologia tradicional serve como base para reformular novas metodologias que atingem novos nichos de usuários, como acontece com a IHC feminista, que será foco neste artigo

\section{IHC Feminista}

A IHC feminista, segundo [6] utiliza as metodologias clássicas da interação humano computador e conceitos anteriormente apresentados, mas as reformula de forma a atender melhor a todos os usuários. Esta utiliza as teorias feministas que se baseiam em igualdade de gênero, procurando entender os conceitos psicológicos, sociológicos e humanos, em torno da visão do usuário sobre determinado sistema.

Neste contexto, as principais diferenças entre metodologias de IHC tradicional e metodologia de IHC feminista são que enquanto a metodologia tradicional reforça estereótipos, muitas vezes separando o sistema de acordo com o segmento atribuído àquele usuário, a metodologia feminista busca a integração entre segmentos em um mesmo sistema. A metodologia tradicional possui objetos de design padronizados, com foco na funcionalidade, enquanto a metodologia feminista busca utilizar objetos que focam em como o usuário pensa e no que ele quer, ou seja, de acordo com suas emoções e necessidades. É como o usuário visualiza o sistema. Essa padronização foi importante para a construção das abordagens em torno da área, para se determinar objetivos, formas e definições. A problemática, no entanto, conflita com o fato dos usuários pensarem de maneira distinta e terem visões diferentes sobre como utilizar determinado sistema.

[7] apresenta os focos principais da abordagem feminista em IHC que caracterizam o diferencial da metodologia:

1. Pluralismo: trabalhar com a diversidade;

2. Participação: representa a valorização dos processos de participação na criação e avaliação de protótipos de design de interface;

3. Ativismo: busca-se soluções de não opressoras e que representam empoderamento;

4. Ecologia: significar o uso de um determinado artefato, incorporar um valor feminino a ele;

5. Corporificação: focar no emocional do usuário, na representação de quem ele é;

6. Posicionamento: conscientizar o usuário sobre as funcionalidades e características do sistema.
O estudo de IHC feminista é importante para a inclusão não só da mulher no sistema, mas também de todos os grupos de usuários que são de certa forma excluídos no contexto digital. O uso da IHC feminista transforma a usabilidade do sistema em questão, pois aproxima a máquina da realidade do usuário, baseado nas suas emoções e não nas suposições. Alguns sistemas vêm sendo remodelados nesse quesito, e na maioria das vezes isso se dá pelo uso de teorias feministas.

\section{IHC Feminista e Redes Sociais}

Segundo [8] as redes sociais se tornaram o meio mais utilizado e popular para disseminar informações servindo como facilitadores de interações sociais, fornecendo uma contribuição para a visão de comportamento, experiências, opiniões e interesses dos usuários. A contribuição e as atividades do usuário fornecem uma visão valiosa do comportamento, experiências, opiniões e interesses.

Pessoas com diferentes características no mundo, como raça e personalidade, fazem escolhas diferentes sobre auto apresentação online, e não apenas sua própria representação, mas a de seus amigos pode influenciar percepções de um público dentro da rede. Embora muitas dessas informações sejam opcionais, o modelo molda os tipos de informações que as pessoas podem fornecer, como eles podem se categorizar e o que irão aprender sobre os outros [9].

Foi realizada uma pesquisa tendo como principal instrumento um questionário online. $\mathrm{O}$ objetivo desta pesquisa era de extrair informações dos usuários da rede social Facebook a partir de uma perspectiva da IHC feminista. O Facebook é uma rede social criada em 2004, por Mark Zuckerberg e ainda está classificada em primeiro lugar como mídia social com 1,65 bilhão de usuários ativos mensais e 1,09 bilhão de usuários ativos diários [10].

$\mathrm{Na}$ pesquisa realizada, não houve diferenciação de sexo e gênero, todos os respondentes tiveram acesso ao mesmo questionário, como teoriza a IHC feminista. As perguntas e análises foram feitas de acordo com as 10 heurísticas de usabilidade de Nielsen atribuindo conceitos de IHC feminista propostos por Bardzell. Esta junção foi feita exclusivamente no trabalho, partindo da premissa de buscar respostas para teoria feminista aplicada na interface e meios de aprimorar a rede social.

\section{Pesquisa}

Este trabalho é resultado do Trabalho de Conclusão de Curso de Bacharelado em Tecnologias da Informação e Comunicação de uma das autoras. A pesquisa tem caráter exploratório, que segundo [11] "O objetivo de uma pesquisa exploratória é familiarizar-se com um assunto ainda pouco conhecido, pouco explorado", aqui caracterizado pela IHC feminista. Como quase todas as pesquisas deste caráter, este trabalho utiliza-se de estudo de caso, que são apontados por [11] com propósitos como:

1. Explorar situações da vida real cujos limites não estão claramente definidos;

2. Preservar o caráter unitário do objeto estudado; 
3. Descrever a situação do contexto em que está sendo feita uma determinada investigação;

4. Formular hipóteses ou desenvolver teorias;

5. Explicar as variáveis causais de determinado fenômeno em situações complexas que não permitam o uso de levantamentos e experimentos. [11]

A coleta de dados tem caráter qualitativa e quantitativa, já que as questões utilizam da liberdade do usuário de expressar determinada opinião, porém estas são agrupadas quando parecidas, formando uma síntese quantitativa importante para resultados mais específicos. Uma pesquisa qualitativa tem como objetivo principal interpretar o fenômeno que observa [11]. Já uma pesquisa quantitativa é "quando predominam métodos estatísticos, cálculos e variáveis bem definidas." [12]. Assim, revisaram-se meios concretos de obter resultados a partir de métodos que aplicassem a teoria feminista, mas não se altera tanto o padrão utilizado. O questionário, foi criado com a ferramenta google forms. As primeiras perguntas foram básicas e focadas no usuário que pudessem expressar sua visão em relação ao Facebook de forma livre. As questões foram apresentadas nas tabelas 1,2,3 e 4:

\begin{tabular}{|l|}
\hline 1. Qual a sua Idade? \\
\hline 2. Gênero: \\
\hline 3.Você utiliza o Facebook? \\
\hline 4.Para qual fim você utiliza o Facebook? \\
\hline 5.Quanto tempo você passa no Facebook por dia? \\
\hline 6.Existe alguma outra rede social que você usa e prefere? \\
\hline 7.Se sim, qual? \\
\hline $\begin{array}{l}\text { 8.Qual a funcionalidade você acrescentaria ao Facebook se } \\
\text { pudesse? }\end{array}$ \\
\hline
\end{tabular}

\section{Tabela 1: Primeira Parte do Questionário}

Na classificação da interface do Facebook o usuário poderia responder por nível de concordância, utilizando a escala likert invertida. Quanto mais à esquerda mais próximo do "concordo fortemente" com determinada questão, quanto mais próximo à direita "discordo fortemente".

\begin{tabular}{|l|}
\hline CLASSIFIQUE A INTERFACE DO FACEBOOK \\
\hline $\begin{array}{l}\text { 1. O Facebook te mantém informado com linguagem apropriada } \\
\text { sobre o que está acontecendo em sua interface, respeitando sua } \\
\text { opinião e participação em tempo real e de acordo com suas } \\
\text { atividades? }\end{array}$ \\
\hline $\begin{array}{l}\text { 2. O Facebook possui uma linguagem clara, com palavras e } \\
\text { símbolos, respeitando: sentimento, gênero e diversidade? }\end{array}$ \\
\hline
\end{tabular}

3. O Facebook te permite liberdade de navegação e escolha do que de fato é importante para você de maneira clara e prática?

4. O Facebook é consistente em relação aos objetos de interação respeitando o seu conhecimento e não o oprimindo?

5. O Facebook avisa sobre erros, prevenindo-o com antecedência respeitando sua diversidade e seu posicionamento?

6. O Facebook é bom com relação aos: objetos, opções e ações visíveis, sem necessitar que você lembre onde se encontra determinada opção, empoderando-o?

7. O Facebook atende suas necessidades de forma satisfatória e sem perder tempo?

8. O Facebook traz apenas informações relevantes e necessárias com diálogo claro e com design satisfatório, respeitando a diversidade?

9. O Facebook ajuda na resolução e diagnóstico de erros incorporando o seu nível de entendimento e não o oprimindo-o?

10. O Facebook traz documentação para busca e ajuda na sua atividade, com acesso rápido e respeitando seu jeito de ver o sistema?

\section{Tabela 2: Segunda Parte do Questionário}

As outras perguntas foram em relação à postagem de fotografias e aos botões de reação do Facebook, onde cada entrevistado poderia atribuir uma opção de reação a cada foto, e descrever seus sentimentos.

Botões de reação são alternativas que o Facebook criou para a funcionalidade "curtir" em determinada postagem. Esta funcionalidade permite ao usuário expressar seu sentimento em relação a um conteúdo, respeitando sua diversidade. A última atualização do Facebook já traz essa opção para curtidas nos comentários, mas até o momento da pesquisa não existia.

Escolha sua reação para a imagem:

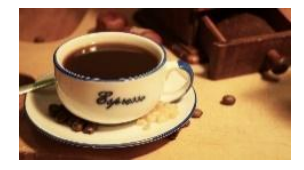




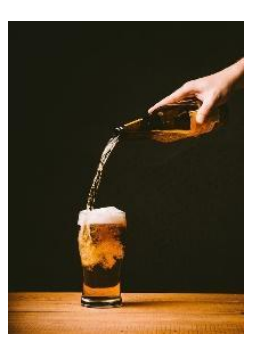

a. Descreva seu sentimento em relação a imagem da cerveja de forma sucinta.

b. Agora pense, você curtiria essa foto ou comentaria só porque um amigo próximo postou, mesmo se não lhe interessasse, só para satisfaze-lo?

*Todas as imagens do questionário foram retiradas do site Pixabay (https://pixabay.com/pt/), que possui acervo de fotos gratuito.

\section{Tabela 3: Terceira Parte do Questionário}

Para finalizar o questionário foram realizadas perguntas complementares sobre o Facebook e sua relação com o usuário, focando na IHC feminista.

Na sua opinião o que falta na interface do Facebook, pensando nas funções dos seus objetos de interação?

a) aceitar as diversidades, propondo diversas interações

b) incluir pessoas com vários tipos de nível de conhecimento

c) não oprimir o usuário

d) determinar a importância de objetos de interação e sua funcionalidade

e) pensar no sentimento do usuário em relação as suas funções

f) conscientizar sobre como o sistema opera e pode afetar um usuário

Defina o Facebook com uma palavra de acordo com o que você sente ao acessá-lo:

\section{Tabela 4: Quarta Parte do Questionário}

A partir do reconhecimento das heurísticas propostas na metodologia clássica por Nielsen, foi pensado em maneiras de integrar a elas as teorias feministas estudadas ao longo do projeto, levando em consideração os focos da IHC feminista propostos por Bardzell, definidos anteriormente (pluralismo, participação, ativismo, ecologia, corporificação e posicionamento).

\section{Análise e Resultados}

As perguntas eram focadas na interface do Facebook e no que o usuário sente ao acessá-lo. Este questionário foi respondido por 206 pessoas, respeitando suas diversidades, e percebendo que ainda há muitas dúvidas e certo preconceito em tratar de questões relacionadas à diversidade de gêneros. A aplicação é parte do trabalho de conclusão de curso de uma das autoras [13] e foi aplicado no período de agosto à outubro de 2016. Foram convidados a participar da pesquisa em torno de 1000 usuários da ferramenta, mas apenas $25 \%$ se disponibilizaram a responder. As perguntas, como observadas no tópico anterior, foram de caráter qualitativo e quantitativo, onde se sintetizou os resultados com o intuito de agrupar respostas e respeitar a opinião de cada usuário. Nesta análise, mostram-se os gráficos das questões com resultados mais relevantes, e outros são brevemente comentados.

A maioria dos respondentes são pessoas que utilizam o Facebook com grande frequência e que eventualmente puderam se deparar com questões relevantes para a pesquisa. A maioria dos respondentes $(73,2 \%)$ tem entre 18 e 23 anos. Os demais $(26,8 \%)$ faziam parte do grupo de pessoas com mais de 32 anos. Ao serem perguntadas sobre seu gênero, 110 pessoas, se identificaram como mulheres, e 92 como homens. Um fator relevante é que algumas pessoas confundiram gênero com orientação sexual, e que apenas duas pessoas responderam como sendo cisgêneras ou transgêneras, conceitos de gênero abordados na teoria feminista, o que mostra que ainda há muito desconhecimento sobre estes conceitos na sociedade.

Dos respondentes, apenas uma pessoa respondeu que não utiliza o Facebook, e 79 utilizam ele para comunicação com outras pessoas, enquanto, 70 para interação, aqui caracterizado por postagens de texto, fotos etc. Outras categorias apareceram como finalidade de uso, conforme mostra a figura 1.

\section{FINALIDADE}

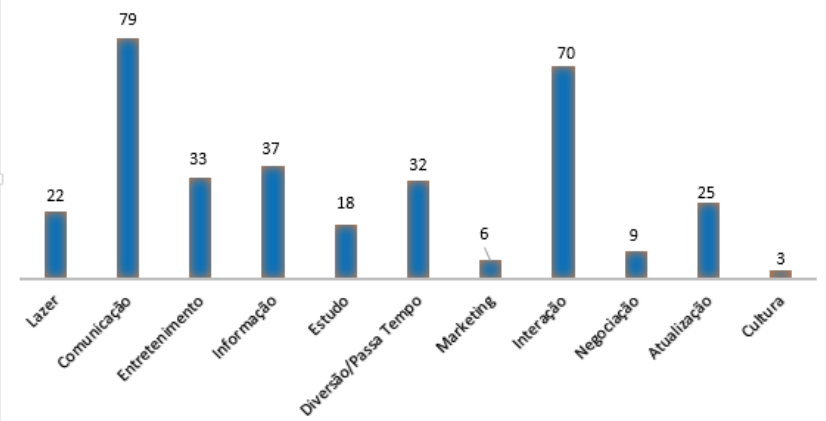

Figura 1: Gráfico da finalidade de uso do Facebook pelos respondentes.

Sobre perguntas gerais ainda foi analisado o tempo diário de uso do Facebook pelos respondentes, que em sua maioria respondeu o tempo de uma a duas horas correntes, ou que utilizam o dia todo em pequenos períodos de tempo, porém estão sempre conectados, pelo computador ou pelo celular. Os celulares facilitaram e muito a vida das pessoas, porque agora elas estão conectadas o tempo todo em seus smartphones. 
Foi analisado também se havia preferência por outra rede social e $58.3 \%$ responderam que preferem de fato outras redes sociais, em sua maioria o Instagram, o Twitter, e o Snapchat, como mostrado na figura 2 .

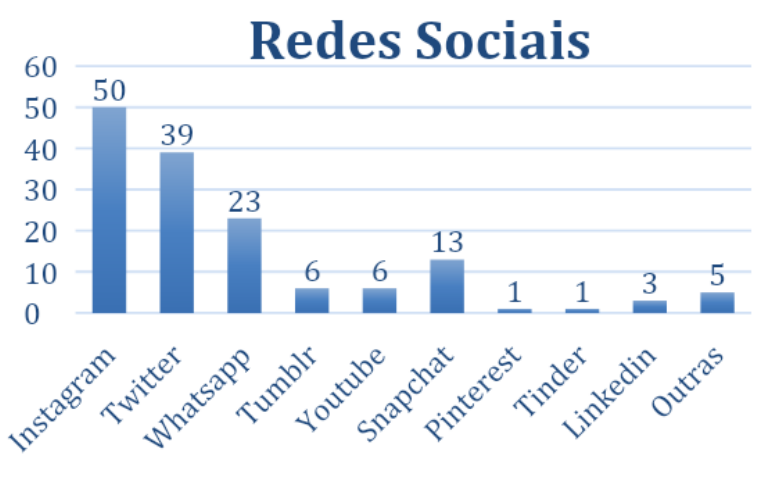

Figura 2: Gráfico das Redes Sociais mais utilizadas pelos respondentes

Ao serem questionadas sobre o que falta no Facebook, algumas respostas interessantes chamaram atenção como: "Mostrar visitantes do perfill", "Bloquear publicidade e conteúdo que não interessa ao usuário ou que os desrespeitem", "Incluir funcionalidade de outros aplicativos ou ferramentas", "Aumentar a quantidade de botões de reações que representam o sentimento do usuário e aplicá-los a comentários" e "Exposição de imagem, acho que quando você é exposto de alguma maneira, seja por meio de vídeo ou foto, a parte de "denúncia" deveria haver a opção de você solicitar e o Facebook retirar postagens que o expõe, mesmo que eles achem que não fere as normas de segurança da rede social, pois eles não podem escolher o que nos fere emocionalmente ou não", provando que existe uma distância, ainda que curta, do Facebook com a realidade dos seus usuários.

É importante salientar que apenas alguns campos foram colocados como obrigatórios, por ser esse um dos propósitos da teoria de IHC feminista, dar liberdade ao usuário de poder responder como se sente à vontade. As perguntas de caráter obrigatório receberam essa tipologia por se tratar de classificação, que representam o propósito principal deste trabalho, onde os gráficos mais relevantes serão mostrados a seguir. A pergunta de caráter classificatório teve como objetivo integrar as 10 heurísticas de Nielsen com os focos da IHC feminista proposto por Bardzell, como mostrado anteriormente, e realizar uma avaliação do Facebook em relação a estes quesitos. A classificação foi de 1 a 5 , quanto mais próximo do 1, maior o grau de concordância, e quanto mais próximo do 5 maior o de discordância com a questão, como citado anteriormente.

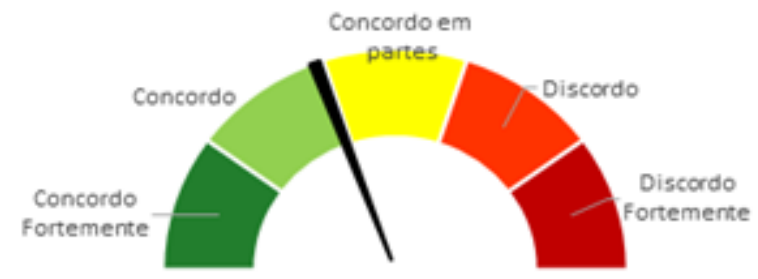

Figura 3: Pergunta 1 - O Facebook te mantém informado com linguagem apropriada sobre o que está acontecendo em sua interface, respeitando sua opinião e participação em tempo real e de acordo com suas atividades?

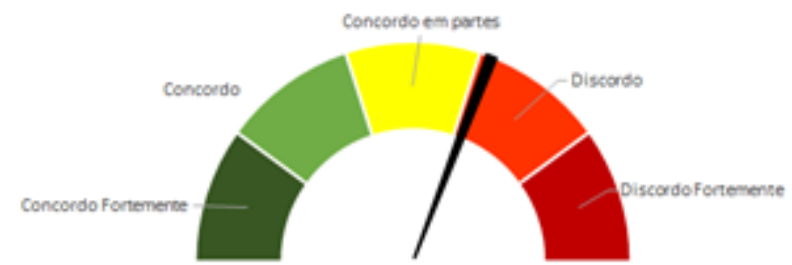

Figura 4:O Facebook avisa sobre erros, prevenindo-o com antecedência respeitando sua diversidade e seu posicionamento?

Nos gráficos das perguntas 1 e 5 (Figura 3 e 4) foram identificadas grandes divergências entre usuários. Enquanto no primeiro os usuários concordavam por parte do Facebook com o usuário e a forma que ele entende a interface, a pergunta 5 gerou um grau de discordância, sobre o Facebook não avisar sobre eventuais erros respeitando o posicionamento de cada um e o nível de dificuldade deste.

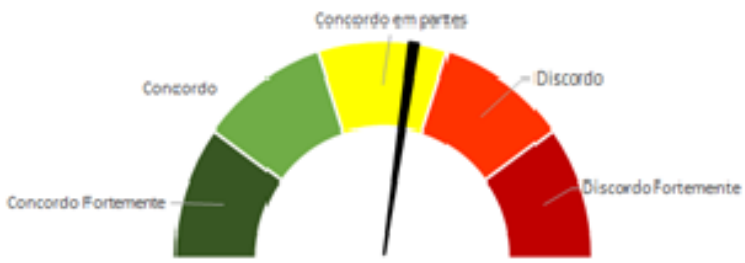

Figura 5: Pergunta 8 - O Facebook traz apenas informações relevantes e necessárias com diálogo claro e com design satisfatório, respeitando a diversidade? 


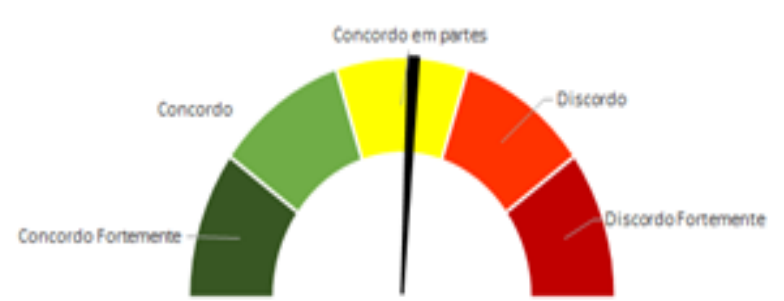

Figura 6: Pergunta 9 - O Facebook ajuda na resolução e diagnóstico de erros incorporando o seu nível de entendimento e não o oprimindo-o?

Apesar do respaldo positivo recebido pelos respondentes em relação à interface do Facebook o restante das questões ficaram com maior porcentagem no nível 3 como mostram os gráficos das perguntas 8 e 9 (Figuras 5 e 6) - com exceção da pergunta 2 que teve um grau alto de concordância - o que nos mostra o grau de incerteza do usuário com a interface, revelando que há muitas melhorias a serem feitas na rede social, principalmente no que se trata de questões de respeito com a diversidade, diálogo e prevenção de erros que possam afetar o sentimento do usuário em questão. Algumas sugestões e observações chamaram atenção como: "Presenciei um episódio em que uma amiga teve uma postagem censurada, por causa de uma música em que as cantoras são trans", provavelmente houve uma quantidade significativa de denúncia neste caso, o que nos mostra que alguns dos problemas são causados pelos seus próprios usuários. Outro entrevistado disse "o Facebook, sendo uma rede social, simula uma sociedade, e o que gera respeito dentro de uma sociedade são as pessoas e não o local onde elas vivem". Este usuário está certo em partes, porque diferente da sociedade real a rede é um algoritmo criado por pessoas, que têm opiniões diversas, e acabam "sem querer" criando uma sociedade do jeito que lhes convêm, provado pelo relato sobre as cantoras trans. Houve também comentários maldosos que provam o quanto a sociedade precisa entender os conceitos da teoria feminista, e a existência de desigualdade de gênero, como: "Parem de mimimi e de ficar querendo inventar um monte de $b^{* * * *}$ afirmando tudo ser modos de opressão. Vão estudar", é claro que a pessoa pode discordar da pesquisa, ela tem liberdade para isso, porém desmerecer um estudo nos mostra que ainda há muitos tabus em relação ao feminismo.

Outras perguntas relevantes para a pesquisa foram sobre o sentimento do usuário com as imagens, que provaram a necessidade de uma maior quantidade de botões de reação no Facebook. Na primeira imagem, que mostrava uma xícara de café, muita gente reagiu com o botão "Curtir", já na segunda que relatava um casamento homo afetivo, houve uma quantidade expressiva de "amei" ou "outro", como mostra o gráfico a seguir.

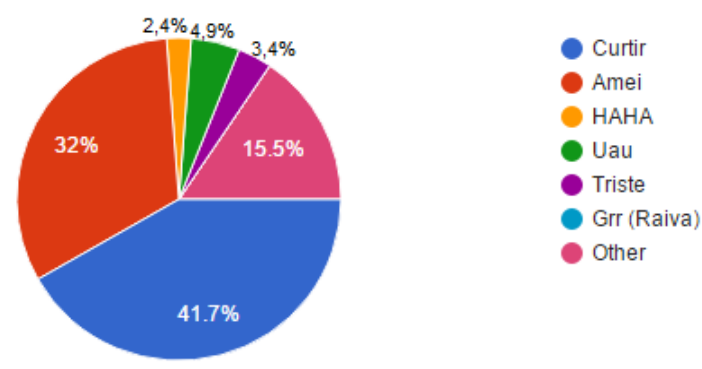

Figura 7: Gráfico de Reações em Imagens

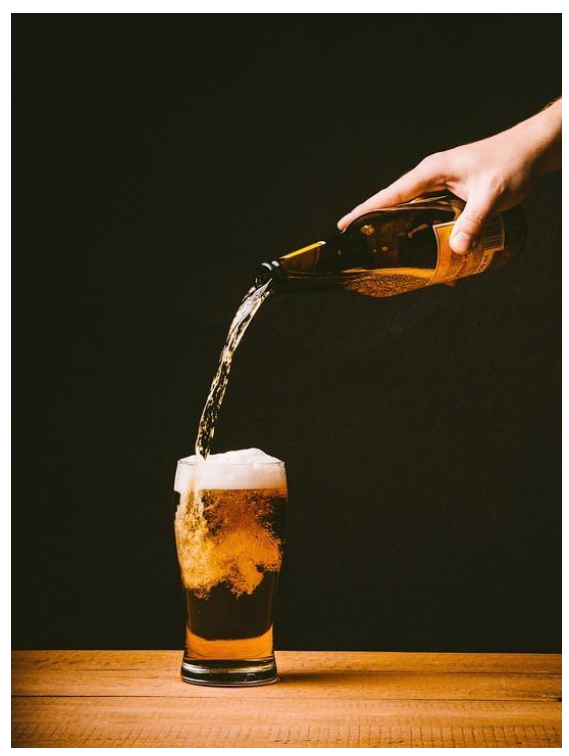

Figura 8: Imagem do questionário

A terceira imagem apresenta uma foto de um fotógrafo profissional, como mostra a figura 8 , que mostra uma cerveja sendo derramada em um copo. Ao perguntar qual seria o sentimento do usuário em relação à imagem, percebe-se uma expressiva quantidade de respostas focadas na opinião sobre a cerveja e não sobre a fotografia em si. Houve uma grande quantidade de respostas como "Quero", "boa", "Não gosto" e até sentimentos de raiva; e poucas respostas como "que fotografia bonita" ou "apesar de não gostar de cerveja, achei a fotografia muito boa". Neste quesito ainda sobre a imagem pergunta-se se o usuário curtiria a foto mesmo se não gostasse dela só para satisfazer um amigo, e apesar da maioria responder que "não" $(70,7)$, houve uma expressiva quantidade de "sim" (29.3\%) aspectos apresentados por [10] que sugere a liberdade de expressão. Essa visibilidade apoia a comparação social e cria práticas e normas altamente visíveis.

Por fim, foram feitas duas perguntas para complementar o estudo, uma colocando como opções os focos da teoria feminista, para que o usuário escolhesse o que falta na interface do Facebook pensando na utilidade de cada um, sendo que poderiam escolher mais de uma opção. O resultado foi que 119 pessoas disseram que 
falta "Conscientizar sobre como o sistema opera e pode afetar um usuário", 70 pessoas colocaram "Aceitar as diversidades, propondo diversas interações", 59 disseram que falta "Pensar no sentimento do usuário em relação as suas funções", 55 que é necessário "Incluir pessoas com vários tipos de nível de conhecimento", 54 falam de "Não oprimir o usuário", e 34 de "Determinar a importância de objetos de interação e sua funcionalidade".

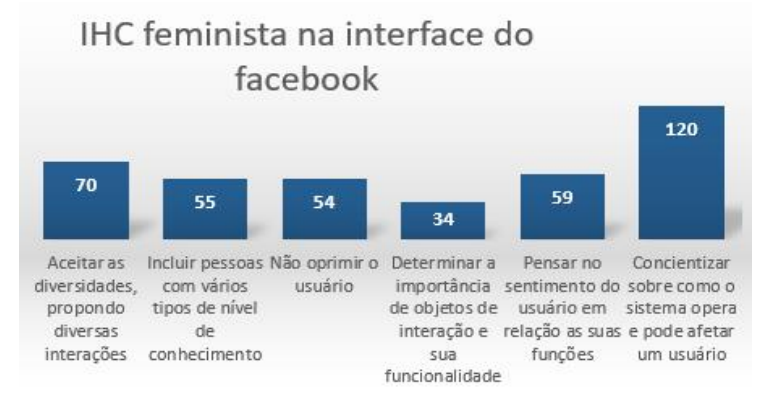

Figura 8: Gráfico sobre IHC feminista no Facebook

A última pergunta foi direcionada ao sentimento do usuário ao utilizar o sistema, com uma palavra que o descreve. As palavras mais utilizadas foram: "Interação", "Informação" e "Diversão" respectivamente. Mas algumas palavras citadas foram relevantes e mostrou a divergência de opiniões sobre a rede social, como "Desconstrução", "Necessário" e "Saudade", mostrando que o sentimento do usuário sobre o sistema é predominante até em questões práticas. Outras análises além dos gráficos foram feitas na interface como o fato, do Facebook não tratar de amores livres, e possibilitar apenas relacionamento sério entre duas pessoas e não mais que isso, gêneros são tratados apenas como feminino e masculino e não como cisgênero e transgênero, além de não permitir ao usuário que escolha como deve ser classificado.

\section{Conclusão}

Com a evolução da tecnologia e necessidade de aprimoramento dos conceitos de Interação Humano Computador, houve uma necessidade de se desenvolver sistemas com foco no usuário. Este artigo, apresentou conceitos de uma metodologia com teoria de IHC feminista. Esta por sua vez, está sendo estudada como base a modificar padrões de gênero no meio digital, isto é, mudar o foco em um determinado tipo de usuário, e se preocupar com todos de forma igualitária, respeitando suas diferenças e sentimentos em relação ao sistema. Neste sentido, este estudo procurou comparar IHC tradicional e a IHC feminista, buscando validar através de questionários realizados com usuários do Facebook - que atualmente é considerado a maior rede social em números de acesso mundial - a fim de sugerir algumas mudanças que atribuíssem o uso da interface com foco na diversidade dos usuários. Percebe-se que os usuários desejam uma necessidade cada vez maior de expressarem seus sentimentos e emoções nas redes sociais. Devese pensar em alternativas de objetos de interação que permitam a liberdade de expressão do usuário.
Algumas melhorias aconteceram no Facebook desde a data de aplicação desta pesquisa. Uma delas foi a inclusão da opção de gênero personalizado considerando a pergunta ao usuário de como ele/ela gostaria de ser tratado pelo sistema. Houve também a inclusão de opções de relacionamento antes inexistentes, de melhorias em questões de privacidade e da atribuição dos stories, famosos no Instagram. Sugere-se como trabalho futuro, reaplicar a pesquisa e fazer uma comparação sobre as mudanças que ocorreram, verificando se houve também mudança na percepção do usuário sobre o sistema, ou se foram apenas recursos adicionais para compor a ferramenta.

\section{AGRADECIMENTOS}

Agradecimentos especiais ao projeto Meninas Digitais - Regional Sul da Universidade Federal de Santa Catarina, campus Araranguá a possibilidade deste estudo e a Coordenação de Aperfeiçoamento de Pessoal de Nível Superior (CAPES) por permitir o andamento de pesquisas após graduação.

\section{REFERÊNCIAS}

[1] J. M. Carrol. 2012. Human Interaction Computer - brief intro. Pennsylvania, USA. https://www.interaction-design.org/literature/book/the-encyclopedia-of-humancomputer-interaction-2nd-ed/human-computer-interaction-brief-intro> Acesso em: setembro de 2016.

[2] S.M. Dray, A. Peer, A. M. Brock, A. Peters, S. Bardzell, M. Burnett, E. Churchill, E. Poole and D. Busse. 2013. Exploring the Representation of Women Perspectives in Technologies. In: CHI 2013 Extended Abstracts, April 27-May 2, Paris, France. DOI: $10.1145 / 2468356.2468799$

[3] N. P. Kotamraju. 2011. Playing stupid, caring for users, and putting on a good show: Feminist acts in usability study work. Interacting with Computers 23 (2011) 439-446

[4] S. Breslin and B. Wadhwa. 2017. Gender and Human-Computer Interaction. $1^{\mathrm{a}}$ ed, dec. 2017 , p. $71-87$

[5] M. Radzikowska, J. Roberts-Smith, X. Zhou and S. Ruecker. 2019. A Speculative Feminist Approach to Design Project Management. Strategic design research jornal, v. $12, \mathrm{n}^{\circ} 1$, jan/abr.2019, p. 94-113.

[6] S. Bardzell and J. Bardzell. 2011. Towards a Feminist HCI Methidology: Social Science, Feminism and HCI. SIGCHI Conference on Human, Vancouver, BC, Canada May 7-12, 2011. DOI: 10.1145/1978942.1979041

[7] S. Bardzell. 2010, Feminist HCI: Taking Stock and outlining an Agenda for Design. CHI 2010, Atlanta USA, April 10-15. DOI: 10.1145/1753326.1753521.

[8] A. Paudel, B. R. Bajracharya, M. Ghimire, N. Bhattarai, D. S. Baral. 2018. Using Personality Traits Information from SocialMedia for Music Recommendation. International Conference on Computing, Communication and Security (ICCCS), Kathmandu - Nepal. 25-27 oct (2018), 116-121 DOI:10.1109/CCCS.2018.8586831

[9] N. A. Van House. 2011. Feminist HCI meets facebook: Perfomativy and social networking sites. Interacting with Computer, apr. 2011, 422-429.

[10] T. Parthornatt, P. Putthapipat, D. Kitsawat and P. Koronjaruwat. 2018. A Smart Home Automation via Facebook Chatbot and Raspberry Pi.International Conference on Engineering Innovation (ICEI), Thailand, 5-6 july, 53-56, DOI:10.1109/ICEI18.2018.8448761

[11] A.C. Gul, 2008. Como elaborar projetos de pesquisa. São Paulo, BR, 2008. https://professores.faccat.br/moodle/pluginfile.php/13410/mod_resource/conte nt/1/como_elaborar_projeto_de_pesquisa_-_antonio_carlos_gil.pdf

[12] G. B. Vilela. 2016. A pesquisa qualitativa. http://docplayer.com.br/1715421-Apesquisa-qualitativa-dr-guanis-de-barros-vilela-junior-guanis-gmail-com.html

[13] F. F. Moro. 2016. Genêro em Redes Sociais: Um incentivo a construção de computação inclusiva, Trabalho de Conclusão de Curso submetido a Universidade 
XI Computer on the Beach

2 a 4 de Setembro de 2020, Baln. Camboriú, SC, Brasil

Moro et al.

Federal de Santa Catarina, Araranguá, SC, Brasil, Dez. 2016.

https://repositorio.ufsc.br/xmlui/handle/123456789/171330

2016.

